\title{
Selection of suitable reference genes for gene expression studies in normal human ovarian tissues, borderline ovarian tumours and ovarian cancer
}

\author{
OLUMIDE OFINRAN ${ }^{1,2^{*}}$, UJJAL BOSE $^{1,3}$, DANIEL HAY $^{1 *}$, SUMMI ABDUL $^{2 *}$, \\ CRISTINA TUFATELLI ${ }^{1}$ and RAHEELA KHAN ${ }^{1 *}$ \\ ${ }^{1}$ Division of Medical Sciences and Graduate Entry Medicine, School of Medicine, The University of Nottingham, \\ Royal Derby Hospital, Derby DE22 3DT; ${ }^{2}$ Department of Gynaecological Oncology, Royal Derby Hospital, \\ Derby DE22 3NE, UK; ${ }^{3}$ Department of Pharmacology, Melaka Manipal Medical College, \\ Manipal, Karnataka 576104, India
}

Received March 14, 2016; Accepted May 9, 2016

DOI: $10.3892 / \mathrm{mmr} .2016 .5933$

\begin{abstract}
The use of reference genes is the most common method of controlling the variation in mRNA expression during quantitative polymerase chain reaction, although the use of traditional reference genes, such as $\beta$-actin, glyceraldehyde-3-phosphate dehydrogenase or 18S ribosomal RNA, without validation occasionally leads to unreliable results. Therefore, the present study aimed to evaluate a set of five commonly used reference genes to determine the most suitable for gene expression studies in normal ovarian tissues, borderline ovarian and ovarian cancer tissues. The expression stabilities of these genes were ranked using two gene stability algorithms, geNorm and NormFinder. Using geNorm, the two best reference genes in ovarian cancer were $\beta$-glucuronidase
\end{abstract}

Correspondence to: Dr Olumide Ofinran, Division of Medical Sciences and Graduate Entry Medicine, School of Medicine, The University of Nottingham, Royal Derby Hospital, Uttoxeter Road, Derby DE22 3DT, UK

E-mail: mide.ofinran@gmail.com

Abbreviations: $\quad$ ACTB,$\quad \beta$-actin; $\quad \mathrm{B} 2 \mathrm{M}, \quad \beta$-microglobulin; BME, $\beta$-mercaptoethanol; $\mathrm{C}_{\mathrm{q}}$, cycle threshold; FIGO, International Federation of Gynecology and Obstetrics; GAPDH, glyceraldehyde-3-phosphate dehydrogenase; GUSB, $\beta$-glucuronidase; HPRT1, hypoxanthine phosphoribosyl transferase-1; M-value, expression stability measure; MIQE, minimum information for publication of quantitative real-time PCR experiments; NHS/HSC, National Health Service/Health and Social care; qPCR, quantitative polymerase chain reaction; $\mathrm{r}^{2}$, coefficient of determination; RT, reverse transcription; rRNA, ribosomal RNA; SV, stability value; totRNA, total RNA

*Contributed equally

Key words: reference genes, housekeeping genes, ovarian cancer, borderline cancer, quantitative polymerase chain reaction and $\beta$-actin. Hypoxanthine phosphoribosyltransferase- 1 and $\beta$-glucuronidase were the most stable in ovarian borderline tumours, and hypoxanthine phosphoribosyltransferase-1 and glyceraldehyde-3-phosphate dehydrogenase were the most stable in normal ovarian tissues. NormFinder ranked $\beta$-actin the most stable in ovarian cancer, and the best combination of two genes was $\beta$-glucuronidase and $\beta$-actin. In borderline tumours, hypoxanthine phosphoribosyltransferase-1 was identified as the most stable, and the best combination was hypoxanthine phosphoribosyltransferase-1 and $\beta$-glucuronidase. In normal ovarian tissues, $\beta$-glucuronidase was recommended as the optimum reference gene, and the most optimum pair of reference genes was hypoxanthine phosphoribosyltransferase-1 and $\beta$-actin. To the best of our knowledge, this is the first study to investigate the selection of a set of reference genes for normalisation in quantitative polymerase chain reactions in different ovarian tissues, and therefore it is recommended that $\beta$-glucuronidase, $\beta$-actin and hypoxanthine phosphoribosyltransferase- 1 are the most suitable reference genes for such analyses.

\section{Introduction}

Ovarian cancer remains a leading cause of death in women, with a $2 \%$ lifetime risk of disease and only a $40 \% 5$-year survival rate. In the United Kingdom, there were over 7,000 new cases of ovarian cancer registered in 2011 (1-3). To date, there is no reliable screening programme, and therefore diagnosis, which requires a high index of suspicion, is difficult. The overall mortality remains high despite newer treatments, since it presents commonly in advanced stages: Therefore, adjuvant treatments post-surgery are almost always required (4). Risk factors for ovarian cancer have been identified, although the initiating mechanism, the origin and the pathogenesis of the disease are poorly understood, and have yet to be elucidated (5).

Uncontrolled cell proliferation, loss of contact inhibition and suppressed programmed cell death associated with gene mutation underlie cancer progression, and this has formed the basis of new therapies targeting ovarian cancer (6). Quantitative 
polymerase chain reaction (qPCR) is an accepted, sensitive technique of quantifying mRNA in biological samples for gene expression analysis $(7,8)$. However, it is not without problems, which may affect the quality of the qPCR experiments. These problems include sample type, sample size, sample collection and preparation and time taken for tissue processing (9). Various fluctuations take place during a qPCR experiment that may result in variations in mRNA expression levels in different samples. These fluctuations are due to genuine biological and mechanical discrepancies, and may lead to biased results, which affect the quality of the qPCR experiments. Previously, qPCR experiments were performed using traditional reference genes, such as $\beta$-actin (ACTB), glyceraldehyde-3-phosphate dehydrogenase (GAPDH), $\beta$-microglobulin (B2M) or 18S ribosomal RNA (18S rRNA) without verification, which also led to unreliable and irreproducible results (10). To avoid this, a definitive method of normalisation was chosen to control for this disparity $(11,12)$. Different strategies have been used for normalising qPCR data, although the use of reference genes is the most common method for reducing and controlling the variation in these RNA levels (8).

Reference genes, previously known as housekeeping genes, are genes that are required for the maintenance of elementary constitutional functions important for the survival of a cell (13). It is important that the reference genes used in qPCR experiments have expression levels that are close to constant across the different tissues being analysed, and the selected reference genes should be validated for each qPCR experiment, since normalisation using numerous meticulously validated reference genes has been shown to result in vastly more accurate results $(8,13-15)$. The suitability of reference genes for the purpose of normalisation, in studying the relative quantification of target genes in gene expression studies in ovarian tissues, including borderline tumour and ovarian cancers, has not hitherto been adequately studied.

The aim of the present study was to select the most suitable reference genes from a set of five probable reference genes for gene expression studies in normal ovarian tissues, borderline ovarian tissues and ovarian cancer tissues, rather than use the traditional reference genes. The reference genes [ACTB, GAPDH, $\beta$-glucuronidase (GUSB), hypoxanthine phosphoribosyl transferase-1 (HPRT1) and B2M] were selected on the basis of their known expression and their common use as reference genes in cancer studies $(10,14,16)$ (Table I). They were investigated to identify the ideal tissue-specific genes, since no generic reference gene exists as several of the most commonly used ones are diverse, resulting in different expression variability under different environmental conditions (17-19).

\section{Materials and methods}

Informed consent. Informed consent was obtained from the subjects for use of their tissues in the present study. A written statement regarding the study was provided, informing the participants of the study and its anonymity.

Tissue samples. A total of 15 fresh frozen ovarian tissue samples were selected for the present study. Ovarian cancer tissues $(n=5)$ and borderline ovarian tumours $(n=5)$ were obtained from patients undergoing primary surgery for suspected ovarian cancer. Normal ovarian epithelial tissue samples $(n=5)$ were obtained from patients undergoing oophorectomy as part of an operation under benign gynaecological conditions (uterine fibroids, uterine prolapse, endometriosis and benign ovarian cysts). All the ovarian cancer tissue samples were serous adenocarcinoma, and the patients had not received any previous treatment; all the normal ovarian tissue samples were confirmed to be free of any disease. The cancers were defined according to the International Federation of Gynecology and Obstetrics (FIGO) staging system (20). All tissue samples were collected from the Royal Derby Hospital, Derby, United Kingdom after obtaining informed consent from each patient. Ethical approval was sought and obtained from the National Health Service/Health and Social Care (NHS/HSC) Research Ethics Committee and the local Research and Development (R\&D) committee of Derby Teaching Hospitals NHS Foundation Trust.

The fresh tissue samples were harvested and snap-frozen immediately at $-80^{\circ} \mathrm{C}$ in liquid nitrogen prior to use in tissue analyses. The samples were homogenised using mechanical disruption; $30 \mathrm{~g}$ ovarian tissue was disrupted by dividing into small fragments with tweezers and a scalpel, and subsequently added to Lysing Matrix D (MP Biomedicals, Santa Ana, CA, USA) and homogenised using tubes pre-filled with ceramic beads containing $600 \mu \mathrm{l}$ Buffer RLT (miRNeasy Mini Kit; Qiagen Gmbh, Hilden, Germany) to which $6 \mathrm{ml}$ of $\beta$-mercaptoethanol was added. Samples were homogenised using an MP Fast-Prep-24 homogeniser (MP Biomedicals) and run at a speed of $6.0 \mathrm{~m} / \mathrm{sec}$ for $40 \mathrm{sec}$. They were then centrifuged at $16,000 \mathrm{xg}$ for $3 \mathrm{~min}$ at $4^{\circ} \mathrm{C}$, and RNA extraction was continued according to the manufacturer's protocols with the extracted total RNA (totRNA) eluted in RNase-free water.

RNA extraction, quantification and integrity. totRNA was extracted from the ovarian tissue samples using commercial spin columns (miRNeasy Mini Kit; Qiagen GmbH) according to the manufacturer's protocol. The concentration and purity of the extracted totRNA representing each sample was measured by spectrometry using a Nanodrop ND-1000 spectrophotometer (Thermo Fisher Scientific, Inc., Wilmington, DE, USA) through absorbance ratio measurements of $A_{260} / A_{280}$. The quality and integrity was assessed by conventional agarose gel electrophoresis (www.thermofisher. com/uk/en/home/references/ambion-tech-support/rna-isolation/tech-notes/is-your-rna-intact.html).

$R T-q P C R$. First-strand complementary DNA (cDNA) was synthesised using a High Capacity ${ }^{\circledR}$ cDNA RT kit (Life Technologies; Thermo Fisher Scientific, Waltham, MA, USA) following the manufacturer's protocol. Each RT reaction was allowed to proceed in a final volume of $20 \mu$ l containing $10 \mu \mathrm{l}$ RNA at a concentration of $120 \mathrm{ng} / \mu \mathrm{l}(1,200 \mathrm{ng}$ totRNA), and the incubations were performed in duplicate. Synthesised cDNA was stored immediately at $-80^{\circ} \mathrm{C}$ when not used for qPCR.

Using the synthesised cDNA as template, qPCR reactions were performed in a final volume of $20 \mu \mathrm{l}$ to determine the expression levels of the five reference genes selected. These experiments were performed in triplicate, with a negative and a no-template control, using the Chromo4 ${ }^{\mathrm{TM}}$ Real-Time 
Table I. Summary of the five evaluated candidate reference genes.

\begin{tabular}{|c|c|c|c|c|}
\hline Symbol & $\begin{array}{l}\text { Gene name } \\
\text { (assay ID) }\end{array}$ & $\begin{array}{l}\text { Location on } \\
\text { chromosome }\end{array}$ & Description & Primer sequence $\left(5^{\prime} \rightarrow 3^{\prime}\right)$ \\
\hline АCТВ & $\beta$-actin & $7 q 22$ & Cytoskeletal structural protein & $\begin{array}{l}\text { F: ATGTGGCCGAGGACTTTGATT } \\
\text { R: AGTGGGGTGGCTTTTAGGATG }\end{array}$ \\
\hline GUSB & $\beta$-D-glucuronidase & 7q21.11 & $\begin{array}{l}\text { Glycosaminoglycan-degrading } \\
\text { hydrolase }\end{array}$ & $\begin{array}{l}\text { F: TGGTGCTGAGGATTGG } \\
\text { R: TGTTGATGGCGATAGTGA }\end{array}$ \\
\hline $\mathrm{B} 2 \mathrm{M}$ & $\beta$-2-microglobulin & $15 q 21$ & $\begin{array}{l}\beta \text {-chain of major } \\
\text { histocompatibility } \\
\text { complex class I molecules }\end{array}$ & $\begin{array}{l}\text { F: TGACTTTGTCACAGCCCAAGATA } \\
\text { R: CGGCATCTTCAAACCTCCA }\end{array}$ \\
\hline GAPDH & $\begin{array}{l}\text { Glyceraldehyde- } \\
\text { 3-phosphate } \\
\text { dehydrogenase }\end{array}$ & $12 \mathrm{p} 13$ & $\begin{array}{l}\text { Oxidoreductase in glycolysis } \\
\text { and gluconeogenesis }\end{array}$ & $\begin{array}{l}\text { F: TCTCCTCTGACTTCAACAGCGAC } \\
\text { R: CCCTGTTGCTGTAGCCAAATTC }\end{array}$ \\
\hline HPRT1 & $\begin{array}{l}\text { HPRT1 } \\
\text { (hypoxanthine } \\
\text { guanine } \\
\text { phosphoribosyl } \\
\text { transferase 1) }\end{array}$ & $\mathrm{Xq} 26.1$ & $\begin{array}{l}\text { Generation of purine } \\
\text { nucleotides }\end{array}$ & $\begin{array}{l}\text { F: TGACACTGGCAAAACAATGCA } \\
\text { R: GGTCCTTTTCACCAGCAAGCT }\end{array}$ \\
\hline
\end{tabular}

F, forward; R, reverse.

Detection system (Bio-Rad Laboratories, Inc., Hercules, CA, USA) attached to a DNA Engine ${ }^{\circledR}$ Peltier Thermal Cycler (Bio-Rad Laboratories, Inc.). The analysed genes were sequence-specific TaqMan ${ }^{\circledR}$ probes, each composed of an oligonucleotide labelled with a fluorescent dye plus a quencher. The respective TaqMan ${ }^{\circledR}$ assay descriptions are shown in Table I. A master mix for each reference gene of interest was first prepared using TaqMan ${ }^{\circledR}$ inventoried Assays-on-Demand probes (Life Technologies; Thermo Fisher Scientific), and the qPCR reactions were performed using a qPCR programme of 40 cycles of $95^{\circ} \mathrm{C}$ for $10 \mathrm{~min} ; 95^{\circ} \mathrm{C}$ for $15 \mathrm{sec}$ and $60^{\circ} \mathrm{C}$ for $1 \mathrm{~min}$, in a final volume of $20 \mu \mathrm{l}$ comprising $18 \mu \mathrm{l}$ Master Mix and $2 \mu \mathrm{l}$ cDNA template.

PCR efficiency. To determine the performance of the qPCR TaqMan ${ }^{\circledR}$ assays, the PCR efficiency of each assay was assessed. A five-point 5-fold dilution series was generated from the cDNA of the tissue samples, and these were run using the standard qPCR protocol described above. The slope, intercept and $\mathrm{r}^{2}$ (coefficient of determination) of the standard curves were calculated, and the qPCR efficiency of each TaqMan ${ }^{\circledR}$ assay was determined from the slopes of the standard curves using the formula: Efficiency $=10^{1} /^{\text {-slope }}-1$.

Analysis of reference gene expression stability. The cycle threshold $\left(\mathrm{C}_{\mathrm{q}}\right)$ is the cycle number at which the fluorescence generated during a qPCR reaction crosses the fluorescence threshold of detection, and this fluorescence greatly exceeds the background fluorescence (21). The threshold cycle is inversely proportional to the amount of original RNA template present in the sample.

$\mathrm{C}_{\mathrm{q}}$ values obtained from the $\mathrm{qPCR}$ experiments were exported into the GeNex software (MultiD Analyses AB, Gothenburg, Sweden) made up of the geNorm and the
Normfinder algorithms, two theoretically different expression ranking stability ranking algorithms based on the principle that ideal reference genes would have similar expression ratios in all experimental environments indicating their expression stability, and none is co-regulated to avoid unreliable results $(17,22)$.

The geNorm algorithm ranks the reference genes according to their M-value (expression stability measure), which is the average pairwise variation of a gene compared with all other tested reference genes, gradually eliminating the gene with the highest M-value that has met the M-value criteria to allow ranking of the tested genes according to this value, with lower values exhibiting higher expression stabilities $(17,22)$.

The NormFinder ranks the set of candidate reference genes according to their expression stability values (SVs) using a combination of intra- and intergroup variation, and this gives an optimum (pair of) reference gene(s) $(23,24)$. The three genes that revealed the highest stability were considered the best combination of reference genes for use in qPCR experiments.

\section{Results}

Tissue samples. The ovarian cancers were staged and graded according to the FIGO staging system. One was stage 3a, one was stage $3 b$ and three were stage $3 c$. There were four grade 3 cancers and one grade 2 ovarian cancer.

RNA purity and quality. The totRNA yield from the ovarian tissue samples ranged from 25.2 to $53.9 \mu \mathrm{g} / \mu 1$, and the spectrophotometric experiments reported RNA with absorbance ratios $\left(\mathrm{A}_{260} / \mathrm{A}_{280}\right)$ of $2.03 \pm 0.02$. This indicated that the totRNAs were of adequate quality and generally free of DNA 
Table II. $r^{2}$ correlation coefficients, signifying how well the data fitted the standard curve.

\begin{tabular}{lccc}
\hline Gene & Slope & Assay efficiency $(\%)$ & Correlation coefficient $\left(\mathrm{r}^{2}\right)$ \\
\hline GAPDH & -3.455 & 94.7 & 0.998 \\
ACTB & -0.343 & 99.1 & 0.999 \\
GUSB & -0.365 & 98.2 & 0.984 \\
HPRT1 & -0.591 & 96.3 & 0.958 \\
B2M & -0.405 & 96.6 & 0.972 \\
\hline
\end{tabular}

An $r^{2}$ value nearer to 1 indicates a better fit of the data to the regression line. PCR efficiency was calculated from the slope of the curve, and a standard curve of slope -3.32 indicates a PCR reaction with $100 \%$ efficiency. $\mathrm{r}^{2}$, correlation coefficient; PCR, polymerase chain reaction; GAPDH, glyceraldehyde-3-phosphate dehydrogenase; ACTB, $\beta$-actin; GUSB, $\beta$-D-glucuronidase; HPRT1, hypoxanthine phosphoribosyl transferase-1; B2M, $\beta$-microglobulin.

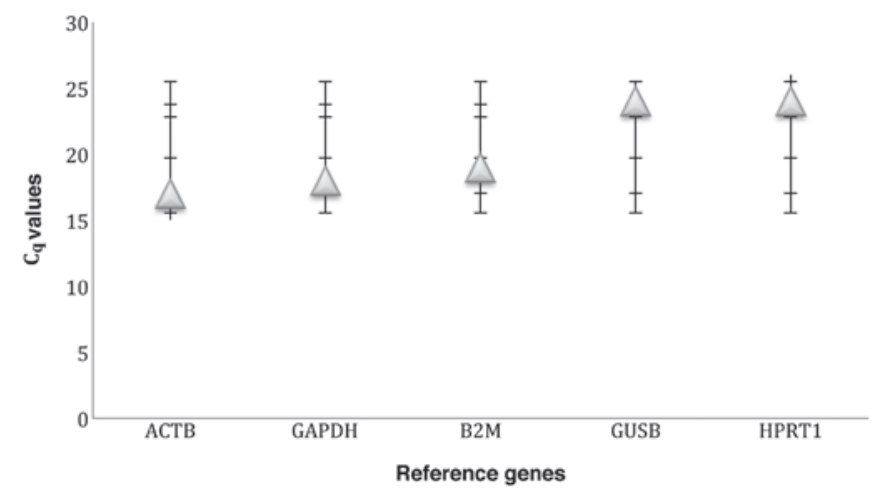

Figure 1. Expression levels of the five candidate reference genes demonstrating the threshold cycle $\left(\mathrm{C}_{\mathrm{q}}\right)$ values, ranging from 15 to 26 cycles.

contamination. Conventional $1 \%$ agarose gel electrophoresis did not reveal any RNA degradation prior to use for reverse transcription.

PCR efficiency. PCR efficiency of the assays calculated from the slope of the standard curves of the serial dilutions ranged from 94 to $99 \%$ with a range of correlation coefficients $\left(\mathrm{r}^{2}\right)$ of 0.958 to 0.999 , demonstrating a comparable performance of the PCR assays (Table II).

Expression levels of candidate reference genes. All the five selected candidate reference genes were expressed in all tissue samples, with various $\mathrm{C}_{\mathrm{q}}$ values ranging from 15 to 26 cycles, demonstrating a wide range of expression (Fig. 1). ACTB, GAPDH and B2M were highly expressed, with average $C_{q}$ values of 20 and below, whereas GUSB and HPRT1 were moderately expressed, with average $\mathrm{C}_{\mathrm{q}}$ values of 24 (Fig. 1).

Stability ranking of the candidate reference genes. To determine the most stable reference genes across the ovarian cancer tissue samples (cancer, borderline cancer and normal), the expression stabilities of the reference genes were investigated by exporting the qPCR data into the GeNex software, and gene stability ranking was conducted using the two reference gene stability analysis algorithms, geNorm and NormFinder.
A

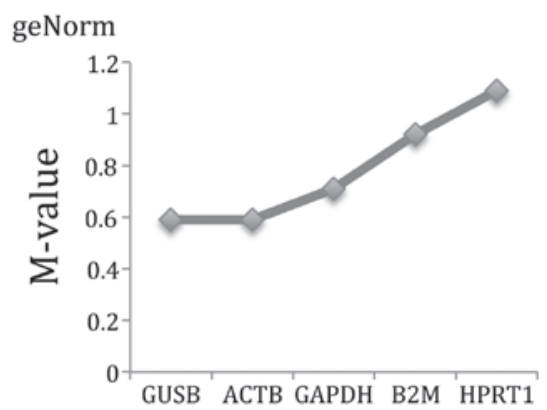

B

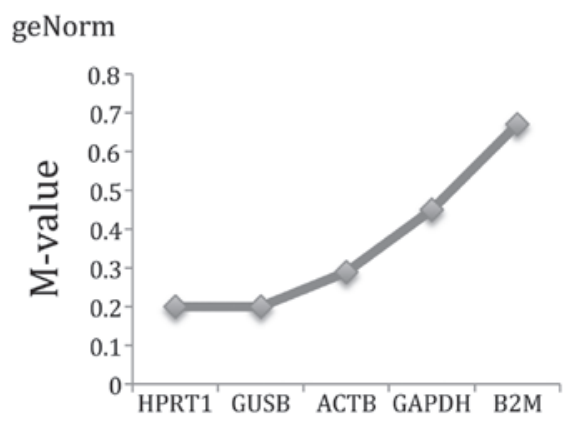

C

geNorm

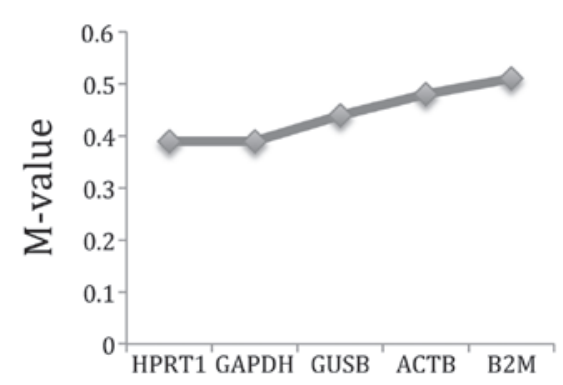

Figure 2. Stability ranking of the candidate reference genes using the geNorm software algorithm. Rankings are represented based on average M-values of the reference genes in (A) ovarian cancer, (B) borderline ovarian cancer and (C) normal ovarian tissues. The genes are ranked from the most (left) to the least (right) stable. M-value, expression stability measure.

geNorm ranking. Using geNorm (Table III and Fig. 2), the five reference genes exhibited $\mathrm{M}$ values $<1.5$ in all the ovarian tissue types. The two best reference genes in the ovarian 
Table III. Stability ranking of the reference genes in all ovarian tissues calculated by geNorm and normfinder.

\begin{tabular}{|c|c|c|c|c|c|c|c|c|c|c|c|c|}
\hline \multirow[b]{2}{*}{ Rank } & \multicolumn{5}{|c|}{ geNorm } & \multicolumn{7}{|c|}{ NormFinder } \\
\hline & Cancer & M & Borderline & M & Normal & M & Cancer & SV & Borderline & SV & Normal & SV \\
\hline 1 & GUSB & 0.59 & HPRT1 & 0.20 & HPRT1 & 0.39 & ACTB & 0.03 & HPRT1 & 0.22 & GUSB & 0.16 \\
\hline 2 & АСТВ & 0.59 & GUSB & 0.20 & GAPDH & 0.39 & GUSB & 0.30 & GUSB & 0.22 & HPRT1 & 0.34 \\
\hline 3 & GAPDH & 0.71 & АСТВ & 0.29 & GUSB & 0.44 & HPRT1 & 0.30 & GAPDH & 0.39 & АСТВ & 0.34 \\
\hline 4 & $\mathrm{~B} 2 \mathrm{M}$ & 0.92 & GAPDH & 0.45 & ACTB & 0.48 & GAPDH & 1.17 & АСТВ & 0.47 & GAPDH & 0.46 \\
\hline 5 & HPRT1 & 1.09 & B2M & 0.67 & B2M & 0.51 & B2M & 1.22 & B2M & 0.99 & B2M & 0.48 \\
\hline
\end{tabular}

M, expression stability measure; SV, stability value; GAPDH, glyceraldehyde-3-phosphate dehydrogenase; ACTB, $\beta$-actin; GUSB, $\beta$-D-glucuronidase; HPRT1, hypoxanthine phosphoribosyl transferase-1; B2M, $\beta$-microglobulin.

A

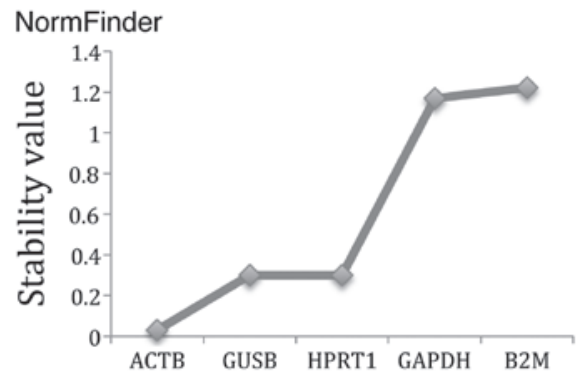

B

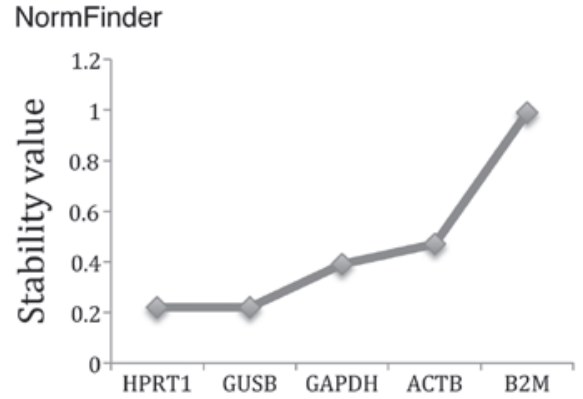

C

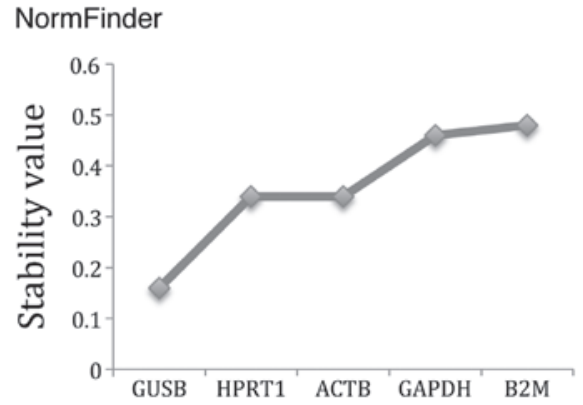

Figure 3. Gene expression stability of the candidate reference genes using the NormFinder software algorithm. Rankings are represented based on average stability values of the reference genes in (A) ovarian cancer, (B) borderline ovarian cancer and $(C)$ normal ovarian tissues. In the graphs, the most stable gene was identified, followed by the best combination of two genes.

cancer tissues selected were GUSB and ACTB, both with the lowest $\mathrm{M}$ value of 0.59 . (Fig. 2A). The third best gene was GAPDH, with an M value of 0.71 . HPRT1 and GUSB were the most stable reference genes in ovarian borderline tumours, with an $\mathrm{M}$ value of 0.20 (Fig. 2B). The third most stable gene was ACTB with an M value of 0.29. HPRT1 and GAPDH were ranked as the most stable in normal ovarian tissues, with an $\mathrm{M}$ value of 0.39 (Fig. 2C). The third most stable gene was GUSB, with an $\mathrm{M}$ value of 0.44 .

NormFinder ranking. NormFinder (Table III, Fig. 3) ranked ACTB as the most stable gene out of the set of five candidate reference genes for use in ovarian cancer tissues, and the best combination of two genes were GUSB and HPRT1. In borderline tumours, HPRT1 was identified as the most stably expressed gene, and the best combination of two genes were HPRT1 and GUSB. In normal ovarian tissues, GUSB was recommended as the optimum reference gene, and the most optimum pair of reference genes was HPRT1 and ACTB (Fig. 3).

\section{Discussion}

Reference gene expression is the recommended method of normalising PCR data (25). However, there is no ideal reference gene, i.e. a reference gene whose expression is constant across all cells and tissues. 'Classical' or 'universal' reference genes, including GAPDH and ACTB, have been demonstrated to be unsuitable for use as reference genes for normalisation in all gene expression studies, as their expression levels have been found to fluctuate in different experimental settings and different tissues (26). Selection of a particular gene, or set of genes, without verification will affect the reproducibility, reliability, accuracy and quality of gene expression analysis. It is therefore very important to carefully select thoroughly validated reference genes prior to performing qPCR experiments. This is one of the recommendations of the minimum information for publication of quantitative real-time PCR experiments (MIQE) guidelines (also including quantification of totRNA to ensure that the identical RNA quantity is used, purity and quality assessment), which stipulates how qPCR experiments should be performed (25).

In the present study, totRNA used for RT was not treated with DNAse, and the results revealed that the totRNA used was almost pure. Agarose gel electrophoresis demonstrated that little, or no, totRNA degradation had occurred. Although there was a slight smeared RNA appearance, there were sharp $28 \mathrm{~S}$ and $18 \mathrm{~S}$ rRNA bands, with a $>2: 1$ 
ratio of high-quality RNA exhibited. RNA degradation was prevented by taking great care during the whole process, collecting and immediately snap-freezing the ovarian tissue samples in liquid nitrogen, and storing them at $-80^{\circ} \mathrm{C}$, adding $\beta$-mercaptoethanol (BME) to the lysis buffer to kill the RNases and help sample stabilisation during extraction, and dissolving the RNA in diethylpyrocarbonate-treated water. Also, on extracting the samples from the freezer, they were not allowed to thaw and were homogenised completely quickly in BME.

An ideal PCR efficiency should be between 90 and $100 \%$, since poor efficiency can result in poor quantification. The results of the present study demonstrated that the PCR efficiency of all the reference genes revealed proportionate performance. This is an important contributor to the proper design of the assays. GeNex software was used to analyse the data, as it is comprises two algorithms, geNorm and NormFinder, which have been identified to be two of the best options for analysing data and recommending the optimum reference genes required for normalisation of $\mathrm{qPCR}$ data $(27,28)$.

The most stable reference genes generated from geNorm and NormFinder software applications revealed a high level of similarity; however, there were subtle disparities in the rank order. This is an accepted outcome due to the different analytical pathways of determining stability by the two algorithms $(29,30)$. On combining the two algorithms, GUSB, ACTB and HPRT1 were revealed to be common to the two programmes, were ranked as the most stable, and were selected as the three most suitable reference genes of choice for normalisation in gene expression studies in ovarian cancer tissues, ovarian borderline tumours and normal ovarian tissues.

One limitation of the present study was that only five candidate reference genes were evaluated: This might be a limitation of the study design, although it is possible that, even if a larger panel of possible genes were analysed, the observations would be supported.

To the best of our knowledge, this is the first study looking at the selection of a set of candidate reference genes for normalisation in gene expression studies in different ovarian tissue disease states. The present study suggested that GUSB, ACTB and HPRT1 are the most stable reference genes of choice, and this is important for the investigation of gene expression in different ovarian tissues.

\section{Acknowledgements}

We would like to thank Dr Ben White, Ave Warren and Rebecca Tarbox, all of the Division of Medical Sciences and Graduate Entry Medicine, School of Medicine, The University of Nottingham, Royal Derby Hospital, Derby, for their assistance with the experiments and advice during the course of this research.

\section{References}

1. Ferlay J, Soerjomataram I, Ervik M, Dikshit R, Eser S, Mathers C, Rebelo M, Parkin DM, Forman D and Bray F. GLOBOCAN 2012 v1.0, cancer incidence and mortality worldwide: IARC Cancerbase no. 11. Lyon, France: International Agency for Research on Cancer, 2013.
2. National Cancer Intelligence Network: Cancer e-Atlas http://www.ncin.org.uk/cancer_information_tools/eatlas/, accessed January 2014.

3. Cancer Statistics Registrations, England (Series MB1): No. 43, 2012.

4. Nossov V, Amneus M, Su F, Lang J, Janco JMT, Reddy ST and Farias-Eisner R: The early detection of ovarian cancer: From traditional methods to proteomics. Can we really do better than serum CA-125? Am J Obstet Gynecol 199: 215-223, 2008.

5. Kurman RJ and Shih IeM: The origin and pathogenesis of epithelial ovarian cancer: A proposed unifying theory. Am J Surg Pathol 34: 433-443, 2010.

6. Evan GI and Vousden KH: Proliferation, cell cycle and apoptosis in cancer. Nature 411: 342-348, 2001.

7. Bustin SA: Absolute quantification of mRNA using real-time reverse transcription polymerase chain reaction assays. J Mol Endocrinol 25: 169-193, 2000.

8. Huggett J, Dheda K, Bustin S and Zumla A: Real-time RT-PCR normalisation; Strategies and considerations. Genes Immun 6: 279-284, 2005 .

9. Bustin SA: Tenth annual nucleic acid-based technologies: Time to stop and think. Washington, DC, USA, 24-26 June, 2002. Expert Rev Mol Diagn 2: 405-408, 2002.

10. Fu J, Bian L, Zhao L, Dong Z, Gao X, Luan H, Sun Y and Song $\mathrm{H}$ : Identification of genes for normalization of quantitative real-time PCR data in ovarian tissues. Acta Biochim Biophys Sin (Shanghai) 42: 568-574, 2010.

11. Dheda K, Huggett JF, Bustin SA, Johnson MA, Rook G and Zumla A: Validation of housekeeping genes for normalizing RNA expression in real-time PCR. Biotechniques 37: 112-119, 2004.

12. Schmittgen TD and Zakrajsek BA: Effect of experimental treatment on housekeeping gene expression: Validation by real-time, quantitative RT-PCR. J Biochem Biophys Methods: 46: 69-81,2000.

13. Eisenberg E and Levanon EY: Human housekeeping genes, revisited. Trends Genet 29: 569-574, 2013.

14. Li YL, Ye F, Hu Y, Lu WG and Xie X: Identification of suitable reference genes for gene expression studies of human serous ovarian cancer by real-time polymerase chain reaction. Anal Biochem 394: 110-116, 2009.

15. Pfaffl MW: Quantification strategies in real-time PCR. AZ of quantitative PCR 1: 89-113, 2004.

16. Ohl F, Jung M, Xu C, Stephan C, Rabien A, Burkhardt M, Nitsche A, Kristiansen G, Loening SA, Radonić A and Jung K: Gene expression studies in prostate cancer tissue: Which reference gene should be selected for normalization? J Mol Med 83: 1014-1024, 2005.

17. Vandesompele J, De Preter K, Pattyn F, Poppe B, Van Roy N, De Paepe A and Speleman F: Accurate normalization of real-time quantitative RT-PCR data by geometric averaging of multiple internal control genes. Genome Biol 3: RESEARCH0034, 2002.

18. Radonić A, Thulke S, Mackay IM, Landt O, Siegert W and Nitsche A: Guideline to reference gene selection for quantitative real-time PCR. Biochem Biophys Res Commun 313: 856-862, 2004.

19. Bustin SA and Nolan T: Pitfalls of quantitative real-time reverse-transcription polymerase chain reaction. J Biomol Tech 15: 155-166, 2004.

20. Prat J; FIGO Committee on Gynecologic Oncology: Staging classification for cancer of the ovary, fallopian tube, and peritoneum. Int J Gynaecol Obstet 124: 1-5, 2014.

21. Tan SC, Carr CA, Yeoh KK, Schofield CJ, Davies KE and Clarke K: Identification of valid housekeeping genes for quantitative RT-PCR analysis of cardiosphere-derived cells preconditioned under hypoxia or with prolyl-4-hydroxylase inhibitors. Mol Biol Rep 39: 4857-4867, 2012.

22. Żyżyńska-Granica B and Koziak K: Identification of suitable reference genes for real-time PCR analysis of statin-treated human umbilical vein endothelial cells. PLoS One 7: e51547, 2012.

23. Andersen CL, Jensen JL and Ørntoft TF: Normalization of real-time quantitative reverse transcription-PCR data: A model-based variance estimation approach to identify genes suited for normalization, applied to bladder and colon cancer data sets. Cancer Res 64: 5245-5250, 2004.

24. Saha P and Blumwald E: Assessing reference genes for accurate transcript normalization using quantitative real-time PCR in pearl millet (Pennisetum glaucum (L.) R. Br). PLoS One 9: e106308, 2014. 
25. Bustin SA, Benes V, Garson JA, Hellemans J, Huggett J, Kubista M, Mueller R, Nolan T, Pfaffl MW, Shipley GL, et al: The MIQE guidelines: Minimum information for publication of quantitative real-time PCR experiments. Clin Chem 55: 611-622, 2009.

26. Radonic A, Thulke S, Mackay IM, Landt O, Siegert W and Nitsche A: Guideline to reference gene selection for quantitative realtime PCR. Biochem Biophys Res Commun 313: 856-862, 2004.

27. Pérez R, Tupac-Yupanqui I and Dunner S: Evaluation of suitable reference genes for gene expression studies in bovine muscular tissue. BMC Mol Biol 9: 79, 2008.
28. Tang R, Dodd A, Lai D, McNabb WC and Love DR: Validation of zebrafish (Danio rerio) reference genes for quantitative real-time RT-PCR normalization. Acta Biochim Biophys Sin (Shanghai) 39: 384-390, 2007.

29. Cruz F, Kalaoun S, Nobile P, Colombo C, Almeida J, Barros LM, Romano E, Grossi-de-Sá MF, Vaslin M and Alves-Ferreira M: Evaluation of coffee reference genes for relative expression studies by quantitative real-time RT-PCR. Mol Breed 23: 607-616, 2009.

30. Kurman RJ and Shih IM: The origin and pathogenesis of epithelial ovarian cancer: A proposed unifying theory. Am J Surg Pathol 34: 433-443, 2010. 